\title{
Does left atrial appendage occlusion influence left atrial hemodynamics? Pilot results of invasive intra-cardiac measurements
}

\author{
Samuel Heuts ${ }^{1}$, John Heijmans ${ }^{1}$, Mark La Meir ${ }^{2}$, and Bart Maesen ${ }^{1}$ \\ ${ }^{1}$ Maastricht UMC+ \\ ${ }^{2}$ UZ Brussel
}

February 5, 2021

\begin{abstract}
Introduction Although left atrial appendage (LAA) obliteration is the cornerstone of stroke prevention in surgical treatment of atrial fibrillation (AF), little is known about its direct impact on hemodynamics. In the current pilot study, we evaluated the hemodynamic effect of LAA closure by clipping in patients undergoing hybrid AF ablation. Methods Seven patients with paroxysmal or persistent AF were included. Hemodynamic and intracardiac pressure measurements such as systemic, pulmonary artery (PA), central venous and LA pressure, cardiac output and indexed left ventricular stroke volume (LVSVi) were measured directly before (T0) and after (T1), and 10 minutes after (T2) LAA closure. Results Of the 7 patients (median 66 yrs), 5 were in AF at the time of incision. There were no differences between T0 and T1, T1 and T2 and T0 and T2 for LA pressure, mean PA pressure, LVSVi and other hemodynamic parameters such as central venous oxygenation and pressure, or systemic arterial pressure. Conclusion In this pilot study, the direct hemodynamic effect of LAA closure is evaluated for the first time. Clipping of the LAA is safe and does not directly affect hemodynamic and intracardiac pressures.
\end{abstract}

Does left atrial appendage occlusion influence left atrial hemodynamics?

Pilot results of invasive intra-cardiac measurements

Samuel Heuts, MD, $\mathrm{PhD}^{1^{*}}$, John H. Heijmans, MD, $\mathrm{PhD}^{2^{*}}$, Mark La Meir, MD, $\mathrm{PhD}^{1,3}$

and Bart Maesen, $\mathrm{MD}, \mathrm{PhD}^{1,4}$

${ }^{1}$ Department of Cardiothoracic Surgery, Maastricht University Medical Center, Maastricht, the Netherlands

${ }^{2}$ Department of Anesthesiology and Pain Management, Maastricht University Medical Center, Maastricht, the Netherlands

${ }^{3}$ Department of Cardiac Surgery, Brussels University Hospital, Brussels, Belgium

${ }^{4}$ Cardiovascular Research Institute Maastricht (CARIM), Maastricht University, Maastricht, the Netherlands.

*denotes equal contribution

Word count:1178

Funding sources: none

Disclosures:: Mark La Meir and Bart Maesen are consultant for Atricure

Correspondence to:

Bart Maesen, MD, PhD 
Department of Cardiothoracic Surgery

Maastricht University Medical Center+

6229 HX, Maastricht, the Netherlands

E: b.maesen@mumc.nl

STRUCTURED ABSTRACTIntroduction Although left atrial appendage (LAA) obliteration is the cornerstone of stroke prevention in surgical treatment of atrial fibrillation (AF), little is known about its direct impact on hemodynamics. In the current pilot study, we evaluated the hemodynamic effect of LAA closure by clipping in patients undergoing hybrid AF ablation.Methods Seven patients with paroxysmal or persistent $\mathrm{AF}$ were included. Hemodynamic and intracardiac pressure measurements such as systemic, pulmonary artery (PA), central venous and LA pressure, cardiac output and indexed left ventricular stroke volume (LVSVi) were measured directly before $\left(\mathrm{T}_{0}\right)$ and after $\left(\mathrm{T}_{1}\right)$, and 10 minutes after $\left(\mathrm{T}_{2}\right)$ LAA closure. Results Of the 7 patients (median $66 \mathrm{yrs}$ ), 5 were in AF at the time of incision. There were no differences between $T_{0}$ and $T_{1}, T_{1}$ and $T_{2}$ and $T_{0}$ and $T_{2}$ for LA pressure, mean PA pressure, LVSVi and other hemodynamic parameters such as central venous oxygenation and pressure, or systemic arterial pressure. Conclusion In this pilot study, the direct hemodynamic effect of LAA closure is evaluated for the first time. Clipping of the LAA is safe and does not directly affect hemodynamic and intracardiac pressures.

Keywords: left atrial appendage closure, clip, hybrid AF ablation, hemodynamics, left atrium

INTRODUCTION The left atrial appendage (LAA) is the most common site of thrombus formation in non-valvular atrial fibrillation (AF).(1) Therefore, LAA obliteration, either through amputation, stapling or clipping, is routinely being performed in patients with AF to reduce stroke risk.(2) It is known that, on the long term, LAA closure can lead to lower systolic blood pressures(3) and potentially induces volume overload as the LAA is the predominant site of atrial natriuretic peptide (ANP) production in the heart.(4) However, the acute direct hemodynamic effects of its closure are unknown. Therefore, the current pilot study evaluated the direct hemodynamic consequences of LAA closure using hemodynamic and invasive intracardiac pressure measurements during hybrid AF ablation.(5)

\section{MATERIALS AND METHODS}

\section{Patient population}

Seven patients undergoing hybrid AF ablation were included in the current study (see Table 1). Our local ethics committee approved the prespecified study protocol (METC 14-5-078, dated October 10 ${ }^{\text {th }}, 2014$ ).

\section{Surgical procedure}

The surgical procedure was described in detail elsewhere.(6) Before incision, the absence of LAA thrombus is confirmed by trans-esophageal echocardiography (TEE). After surgical AF ablation consisting of bilateral pulmonary vein isolation, and superior and inferior connecting lesions (so-called 'box-lesion') via bilateral thoracoscopy, the LAA is closed using the Atriclip Pro device (Atricure, Mason, OH, USA). Hereafter, endocardial validation of epicardial lesions and touch-up ablation, if needed, is performed.

\section{Echocardiographic evaluation}

All patients underwent pre-operative trans-thoracic echocardiography with extensive atrial and ventricular function and dimension evaluation (Table 1). Per-procedural echocardiographic evaluation was performed with TEE (Epiq 5, Philips, Eindhoven, the Netherlands).

\section{Pressure and hemodynamic measurements}

Systemic arterial pressure was registered by left radial artery catheter (Arrow, Teleflex, Athlone, Ireland), central venous pressure by a central venous catheter in the right jugular vein. Pulmonary artery (PA) pressures were measured by a Swan-Ganz PA catheter (Edwards Lifesciences, Irvine, CA, USA). Cardiac 
output and left ventricular stroke volume (LVSV) were assessed based on arterial pressure derived monitoring (MostCare $^{\text {Up }}$, Vygon, Padua, Italy).

Transseptal puncture was performed by a flexible introducer and needle, through the right femoral vein (Agilix NXT, Abott, Lake Bluff, IL, USA). Intra-atrial location of the pressure wire allowed for precise and direct LA pressure measurements.

All measurements were performed just before LA occlusion $\left(\mathrm{T}_{0}\right), 1$ minute after LA occlusion $\left(\mathrm{T}_{1}\right)$ and 10 minutes after LA occlusion $\left(\mathrm{T}_{2}\right)$.

\section{Statistical analysis}

Given the small study population, all data were presented as median and corresponding ranges. Testing for differences at the different prespecified timepoints was performed by use of the Wilcoxon-signed rank test. A p-value of $<0.05$ was considered statistically significant. Testing was performed for $T_{0}$ versus $T_{1}, T_{1}$ versus $\mathrm{T}_{2}$ and $\mathrm{T}_{0}$ versus $\mathrm{T}_{2}$. Due to the sample size, data were also presented in graphs at the different timepoints for visual assessment. All statistical analyses were performed in SPSS for Mac (SPSS version 27, Armonk, NY, USA). Graphs were realized using GraphPad Prism version 7 (GraphPad software, La Jolla, CA, USA). $\mathrm{Ik}$

\section{RESULTS}

\section{Patients}

In all patients (66 years, range 55-69), the clip size was determined intra-operatively. All but one received a $35 \mathrm{~mm}$ clip (86\%), 5 patients were in AF at the beginning of the surgery (72\%), 2 in sinus rhythm (SR, $28 \%)$.

\section{Invasive measurements}

Systolic LA pressure

There were no significant differences in LA pressure $\left(\mathrm{T}_{0}: 22 \mathrm{mmHg}\right.$, range 13-30; $\mathrm{T}_{1}: 24 \mathrm{mmHg}$, range 15$31 \mathrm{mmHg} ; \mathrm{T}_{2}: 22 \mathrm{mmHg}$, range $15-29 \mathrm{mmHg}$ ) between the different timepoints $\mathrm{T}_{0}$ versus $\mathrm{T}_{1}, \mathrm{~T}_{1}$ versus $\mathrm{T}_{2}$ or $\mathrm{T}_{0}$ versus $\mathrm{T}_{2}(\mathrm{p}=0.131, \mathrm{p}=0.339$ and $\mathrm{p}=0.865$ respectively, Figure $1 \mathrm{~A})$.

Mean PA pressure

There were no differences in mean PA pressures $\left(\mathrm{T}_{0}: 33 \mathrm{mmHg}, 20-48 \mathrm{mmHg} ; \mathrm{T}_{1}: 37 \mathrm{mmHg}, 22-49 \mathrm{mmHg} ; \mathrm{T}_{2}\right.$ : $35 \mathrm{mmHg}, 20-48 \mathrm{mmHg})$ between the timepoints $(\mathrm{p}=0.498, \mathrm{p}=0.414$ and $\mathrm{p}=1.000$ respectively, Figure $1 \mathrm{~B})$.

\section{Indexed LV stroke volume}

There were no significant differences in LVSV indexed (LVSVi) to body surface area (BSA): $\mathrm{T}_{0}: 28 \mathrm{~mL} / \mathrm{m}^{2}$, $20-39 \mathrm{~mL} / \mathrm{m}^{2} ; \mathrm{T}_{1}: 24 \mathrm{~mL} / \mathrm{m}^{2}, 19-33 \mathrm{~mL} / \mathrm{m}^{2} ; \mathrm{T}_{2} 24 \mathrm{~mL} / \mathrm{m}^{2}, 18-31 \mathrm{~mL} / \mathrm{m}^{2} ; \mathrm{p}=0.285, \mathrm{p}=0.581, \mathrm{p}=0.066$ respectively, Figure 1C).

\section{Other measurements}

There was no statistical difference between $\mathrm{T}_{0}$ and $\mathrm{T}_{2}$ for mean systemic arterial pressure $(\mathrm{p}=0.345)$, central venous pressure $(\mathrm{p}=0.496)$ and central venous oxygen saturation $(\mathrm{p}=0.368)$.

\section{DISCUSSION}

The unique setting of hybrid AF ablation facilitates simultaneous measurement of intracardiac pressures.(6) In the current pilot study, direct hemodynamic consequences of LAA obliteration were evaluated for the first time. Surprisingly, no significant changes in hemodynamics or intracardiac pressure measurements were observed directly after and 10 minutes after LAA clipping. 
Neurohormonal, the LAA is the main site of ANP production, and as such, it is perceived that its obliteration can lead to volume overload in the days following surgery. In addition, the LAA also has a contractile function and takes part in the LA contraction process, especially in patients in SR. In patients in SR, LAA ejection fraction (EF) was measured to be $46 \%$, while in the same patients in $\mathrm{AF}$, EF was $26 \%$, demonstrated in an elegant study by Akosah et al.(7).

Potentially, as LAA contractile function is already diminished in patients in AF - five of seven patients in this study were in AF at the time of surgery - its obliteration does not significantly affect LA contractile function in general. Still, our findings seem in line with a previous study by de Maat et al.(8), where LA function was measured only by echocardiography in patients with paroxysmal AF, undergoing this procedure.

\section{Limitations}

The current pilot study included a modest number of patients, which were predominantly in AF. Therefore, it cannot be ruled out that LAA obliteration in larger patient cohorts in SR, does affect hemodynamics. Furthermore, the LAA comes in different sizes and variations, which was not assessed in the current study. It might be possible that its obliteration does have consequences in larger sized LAA's.

\section{CONCLUSION}

This is the first study demonstrating the direct hemodynamic consequences of LA obliteration by intracardiac pressure measurements. Although this pilot study population was modest in numbers, LA obliteration by use of an atrial clip appeared to be safe, without affecting hemodynamic and intracardiac pressures. Future studies with larger patient cohorts are warranted to corroborate these findings.

\section{REFERENCES}

1. Blackshear JL, Odell JA. Appendage obliteration to reduce stroke in cardiac surgical patients with atrial fibrillation. Ann Thorac Surg 1996;61(2):755-759.

2. Cox JL. Mechanical closure of the left atrial appendage: Is it time to be more aggressive? J Thorac Cardiovasc Surg 2013;146(5):1018-1027 e1012.

3. Turagam MK, Vuddanda V, Verberkmoes N, Ohtsuka T, Akca F, Atkins D, Bommana S, Emmert MY, Gopinathannair R, Dunnington G, Rasekh A, Cheng J, Salzberg S, Natale A, Cox J, Lakkireddy DR. Epicardial left atrial appendage exclusion reduces blood pressure in patients with atrial fibrillation and hypertension. Journal of the American College of Cardiology 2018;72(12):1346-1353.

4. Stollberger C, Schneider B, Finsterer J. Elimination of the left atrial appendage to prevent stroke or embolism? Anatomic, physiologic, and pathophysiologic considerations. Chest 2003;124(6):2356-2362.

5. Maesen B, La Meir M. Unilateral left-sided thoracoscopic ablation of atrial fibrillation. Ann Thorac Surg 2020;110(1):e63-e66.

6. Maesen B, Pison L, Vroomen M, Luermans JG, Vernooy K, Maessen JG, Crijns HJ, La Meir M. Three-year follow-up of hybrid ablation for atrial fibrillation. Eur J Cardiothorac Surg 2018;53(suppl_1):i26-i32.

7. Akosah KO, Funai JT, Porter TR, Jesse RL, Mohanty PK. Left atrial appendage contractile function in atrial fibrillation. Influence of heart rate and cardioversion to sinus rhythm. Chest 1995;107(3):690-696.

8. De Maat GE, Benussi S, Hummel YM, Krul S, Pozzoli A, Driessen AH, Mariani MA, Van Gelder IC, Van Boven WJ, de Groot JR. Surgical left atrial appendage exclusion does not impair left atrial contraction function: A pilot study. Biomed Res Int 2015;2015:318901.

\section{TABLES}

Table 1. Baseline and surgical characteristics 


\begin{tabular}{|c|c|c|c|c|c|c|c|c|}
\hline & Sex & Age (years) & $\operatorname{BSA}\left(\mathrm{m}^{2}\right)$ & LVEF (\%) & $\begin{array}{l}\text { LAvol } \\
(\mathrm{mL})\end{array}$ & $\begin{array}{l}\text { LAVI } \\
\left(\mathrm{mL} / \mathrm{m}^{2}\right)\end{array}$ & $\begin{array}{l}\text { Rhythm at } \\
\text { incision }\end{array}$ & $\begin{array}{l}\text { Clip siz } \\
(\mathrm{mm})\end{array}$ \\
\hline $\begin{array}{l}\text { Patient } \\
1\end{array}$ & $\mathrm{M}$ & 68 & 1.96 & 56 & 127 & 65 & $\mathrm{AF}$ & 35 \\
\hline $\begin{array}{l}\text { Patient } \\
2\end{array}$ & $\mathrm{M}$ & 62 & 2.02 & 58 & 102 & 60 & $\mathrm{AF}$ & 35 \\
\hline $\begin{array}{l}\text { Patient } \\
3\end{array}$ & M & 66 & 2.31 & 43 & 89 & 39 & $\mathrm{SR}$ & 40 \\
\hline $\begin{array}{l}\text { Patient } \\
4\end{array}$ & M & 55 & 2.20 & 58 & 66 & 30 & $\mathrm{AF}$ & 35 \\
\hline $\begin{array}{l}\text { Patient } \\
5\end{array}$ & M & 69 & 1.94 & 60 & 95 & 49 & $\mathrm{AF}$ & 35 \\
\hline $\begin{array}{l}\text { Patient } \\
6\end{array}$ & $\mathrm{~F}$ & 68 & 1.77 & 66 & 81 & 46 & $\mathrm{AF}$ & 35 \\
\hline $\begin{array}{l}\text { Patient } \\
7\end{array}$ & $\mathrm{M}$ & 66 & 2.08 & 56 & 78 & 38 & $\mathrm{SR}$ & 35 \\
\hline
\end{tabular}

AF: atrial fibrillation, BSA: body surface are, LAVI: indexed left atrial volume, LAvol: left atrial volume, LVEF: left ventricular ejection fraction, SR: sinus rhythm

\section{FIGURES}

Figure 1. Graphical representation of the different invasive pressure and hemodynamic measurements

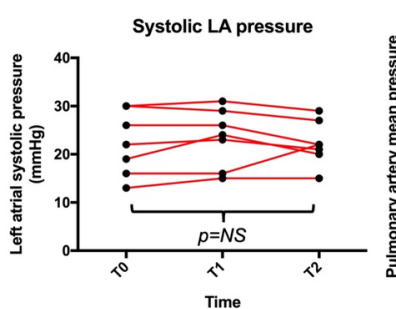

A

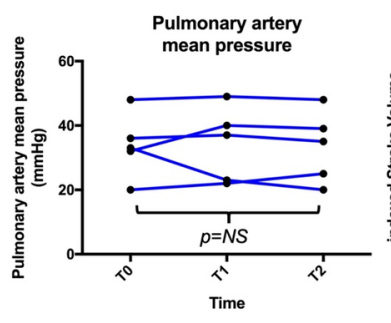

B

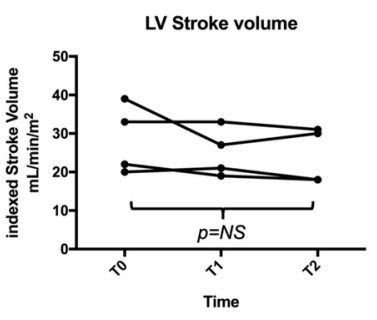

C

NS: non significant. 


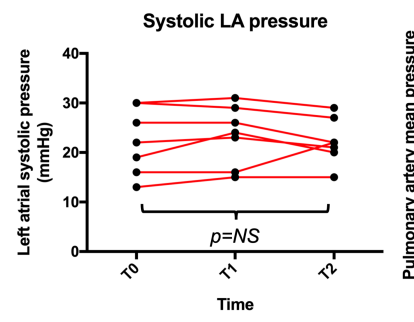

A

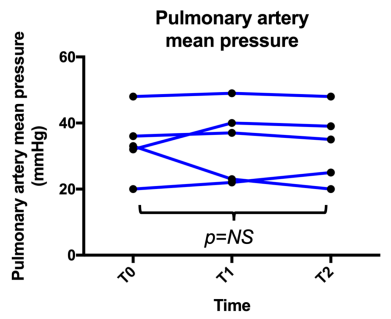

B

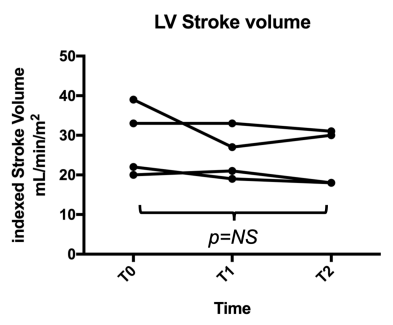

C

\section{Hosted file}

Table 1.pdf available at https://authorea.com/users/394036/articles/507519-does-left-atrialappendage-occlusion-influence-left-atrial-hemodynamics-pilot-results-of-invasive-intracardiac-measurements 